\title{
VERSITA
}

10.2478/v10284-012-0006-y

\section{THE CAPITAL ASSET PRICING MODEL}

THEORY AND EMPIRICAL TESTING ON THE GREEK STOCK EXCHANGE MARKET

TAMARA AYRAPETOVA

In this paper I will cover the main ideas and concepts behind Capital Asset Pricing Model (CAPM) and Portfolio Theory, which gave a great contribution to CAPM development. This paper is based on a presentation and will contain slides, tables, and graphs from the various resources used to create it. 
CAPM was developed by William Sharpe (1964) and John Lintner (1965); later in 1990 this development resulted in a Nobel Prize. The model has brought gradual improvements into the way assets are priced nowadays. CAPM has been based on the earlier works of Harry Markowitz in the 1950s, one of which was called the "Optimization Theory". The most famous and widely used finding of this paper is the MeanVariance Model. This paper was the first theory highlighting the importance of investor risk preferences and the concept of 'diversification' that allowed investors to maximise their profits by finding optimal portfolios for a specific level of risk.

CAPM offers a new way of identifying risk on the securities. It gives a measure of risk in relation to overall market fluctuations. This concept of correlation between price movements of an individual asset/portfolio and the market as a whole, gives the model its main difference from past models in this area and models, which were grounded on CAPM such as the Arbitrage Theory.

Even though CAPM is recognised as one of the most reliable tools for managers and investors to predict the returns on securities and portfolios, there has been a lot of debate if empirical evidence is in support of the model. There have been few case studies and research conducted, which show evidence against the model, but even so, it is still clear that the majority of the times the model gave accurate predictions. Most of the opponents of the model base their arguments on the assumptions of CAPM. They are said to be too general and not reflecting reality by providing idealistic approaches on the way markets work. In this paper we will be able to look at all of the assumptions applied to the case study of the Greek Stock Exchange Market and examine the model's relevance. The main aim of this paper is to go through the crucial concepts constituting CAPM and to apply it to real life examples. Hopefully, by the end of this paper, it will be clear what the weaknesses and strengths of CAPM are.

\section{PORTFOLIO THEORY OR MEAN-VARIANCE MODEL}

In this paper we are looking at CAPM and its application to make sure that we get an accurate understanding of all of the insights of the model, one has to consider looking at the Portfolio Theory developed by Harry Markowitz during the 1950s. Portfolio Theory was the first of its kind trying to justify prices on the risk associated with the security. The theory assumes normal distribution of returns and market efficiency. Efficiency is a central concept in portfolio theory and utility theory, which is based on the idea of the maximisation of profits. The main idea behind Portfolio Theory is 'Don't put all of your eggs in the same basket'. The concept is often referred to as 'diversification' of assets, which played one of the key roles in the progress of asset management and finance as a whole.

Harry Martkowitz (1952) specified two main types of risk in his Optimization Theory. Systematic risk, or also called Market risk, which cannot be eliminated by diversification, and Unsystematic risk, or also called Company Specific risk, which by applying Portfolio Theory, could be reduced or fully eliminated. Portfolio Theory gave a lot more opportunities to investors who were seeking to make profits with lower risk, such investors in Portfolio Theory and later in CAPM are called risk-averse investors. Those investors are seeking to maximise their utility but are not ready to take extra risk.

Later James Tobin (1958) developed Portfolio Theory (see CML p. 9), where he highlighted that it is better to combine risky securities with risk free assets like treasury bills or bonds. This idea gave a significant change to the way investors chose their optimal portfolios for the specific level of risk. This change also impacted on the 'efficiency frontier'. According to the theory, it is possible to construct an 'efficient frontier' of optimal portfolios offering the maximum possible expected return for a given level of risk, as described in the Harry Markowitz (1952) 'Portfolio Selection' Journal of Finance. 


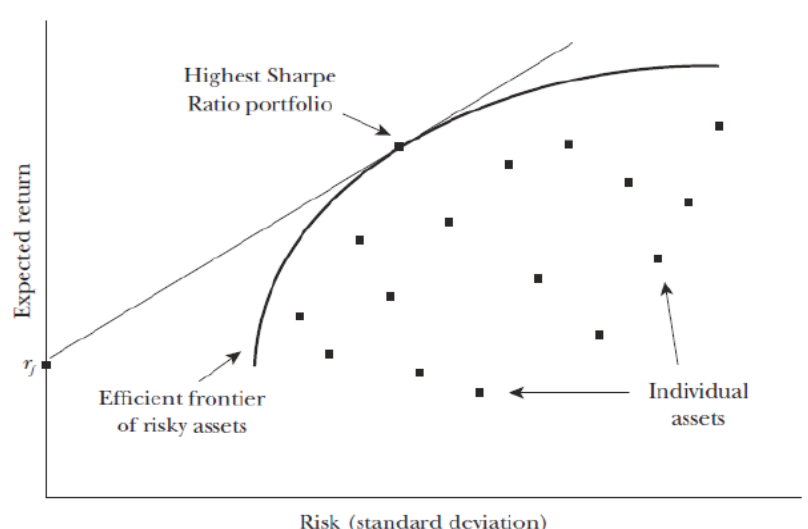

Figure 1: Efficient Frontier with many risky assets.

As has been already mentioned above by introducing the Portfolio Theory, investors are able to combine different securities and construct optimal portfolios. Generally those portfolios will be achieving the same expected returns but at different levels of risk. However, using the Markowitz Optimization Theory we can compute a so called 'efficiency frontier', which can be seen from the Figure 1. In the Figure 2 (below) one can see representation of Investment Opportunities, where 'abc' represents efficiency frontier. The original paper developed by Markowitz assumed that all of the asset combinations are risky. If this is true, then the efficiency frontier can be represented by parabola 'abc' in Figure 2.

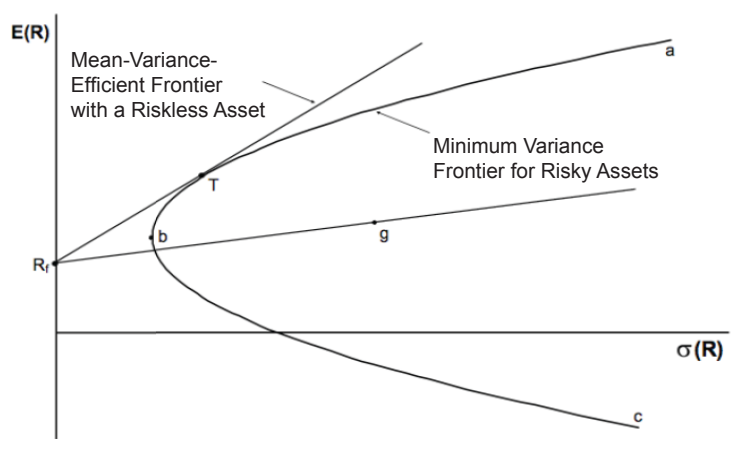

Figure 2: Investment Opportunities.

Only portfolios above b, on the abc, can be taken as mean-variance efficient. However, with the later development of James Tobin (1958) the risk-free asset changed the picture dramatically. The straightline, which goes from Rf towards T, tangency portfolio, or market portfolio, which has the highest Sharpe's ratio, represents the mean-variance efficiency frontier with risk-free security. As the result, Tobin found that an efficient portfolio for all investors will consist of risk-free lending or borrowing and risky market portfolio ' $M$ '. This was a key statement of Tobin's 'Separation Theorem' (1958). The risk-free security is said to minimise the variance on the portfolio. That is why this change has been so vital. CAPM developed by Sharpe and Lintner is based on the later version with the risk-free security, since one of the main assumptions behind CAPM is that investors can borrow and lend unlimitedly at risk-free rate of return. However, there is another CAPM model which we will not focus in this paper, and it excludes the ability of investors to lend and borrow on the risk-free interest rate. This model was developed by Black and is often referred to as Black CAPM. 


\section{STATIC CAPM}

Static CAPM is the original version of CAPM developed by Sharpe and Lintner during the 1960s. Static CAPM assumes that there is an opportunity to borrow and lend unlimitedly at the risk-free interest rate. The key objective of this model is to describe the behaviour of the investor as risk-averse. The theory assumes that since investors are risk-averse they need to be compensated for the additional risk they are taking. This compensation is represented in the model as excess return per unit of risk, which is justified as Beta of an asset. This compensation is called risk premium.

The model looks at the portfolio selection based on the mean-variance criteria. It brings out very crucial aspects of price setting, by giving as a foundation assumptions that set a framework. According to the model, investors have the same mean-variance expectations which are linked to their choice of the portfolio and risky assets. It looks at the volatility and price fluctuations of specific individual portfolios and links them to the market as a whole. This connection between market and portfolio is essential when predicting expected returns on the portfolio and is represented by a correlation coefficient. Correlation is a part of the Beta of the asset; the higher the Beta of the portfolio, the higher the returns and the volatility, and that means higher risk. When a correlation coefficient is bigger than one, the portfolio will tend to outperform the market.

CAPM works only when looking at the equilibrium market. Under equilibrium markets we mean that prices constantly adjust in such a way that demand to hold each assets equals its total stock. The condition of equilibrium markets is the first assumption of CAPM.

\section{ASSUMPTIONS}

When we look at CAPM it is essential to understand the assumptions behind it correctly since a misinterpretation of them can lead to inaccurate forecasts. The model is very restricted by what is assumed to be true. The assumptions can be generally divided into 3 conditions:

Markets are Equilibrium - this concept consists of various factors. First of all, it means that markets have zero transaction costs and short sales are allowed. Both of these assumptions are surely idealised; in this case they are there to show that CAPM is more likely to give accurate forecasts when markets have less friction. Secondly, it means that an investor can borrow and lend unlimitedly at a risk-free rate of return. Thirdly, it means that investors will be able to divide their assets into units. This, as the result, gives them the ability to invest different amounts into various assets. In equilibrium markets all assets can be bought and sold at an observed market price. The price of the asset is not affected by the investor decision, since markets are assumed to be competitive. Finally, taxes are neutral. In this case it does not mean that they are equal to zero, but more importantly, they are the same for all of the investors.

Mean-Variance Portfolio Selection - this condition takes into consideration single-period time horizons. This simply means that investors when invested do not revise their choice of asset. It also means that investors are choosing their portfolios based on mean-variance criteria.

Homogeneous Beliefs - all investors have the same expectations of variance and covariance of asset returns, since as it has been mentioned above, all of the investors are basing their choice on mean-variance criteria; they all choose the same portfolio of risky assets. This portfolio later on will be mentioned as Market Portfolio or Tangency Portfolio. 
Returning to the assumptions of CAPM, one can see that according to CAPM all investors have an equal possibility to invest into a risk-free security like a Treasury bill. In accordance to this concept, the investor can decide to invest a certain proportion of his/her wealth into risk-free security and the rest into risky assets. Since all of the investors have the same expectation of mean-variance, they are going to choose the same portfolio of risky assets, which is usually called a market portfolio. This portfolio is the same for all investors due to their homogeneous beliefs. The market portfolio is considered to be efficient since it consists of efficient portfolios.

If an investor decided to invest in risk-free securities and a Risky Market Portfolio ' $M$ ', then the standard deviation of such a portfolio will be simply the standard deviation of ' $M$ ' multiplied by its weight since the standard deviation of risk-free security is zero.

$$
\begin{gathered}
\sigma p=w \sigma m \\
\sigma p 2=w 2 \sigma m 2
\end{gathered}
$$

Now let us assume that Market Portfolio ' $M$ ' weight is 1 then (1-w) will be the weight of the risk-free asset. Assuming this is true, the expected return on the portfolio $M$ would be expressed through the following equation:

$$
E R p=1-w R^{*}+w E(R m)
$$

This equation then can be rearranged into:

$$
E R p=R^{*}+w E(R m)-R^{*}
$$

This is the equation of Capital Market Line, which we will look at later on in this paper. If we then go back to the variance of the portfolio taking equation 1 , we can rearrange it into:

$$
\begin{gathered}
\sigma p 2=w 2 \sigma m 2 \\
w=\sigma p \sigma m
\end{gathered}
$$

Substituting the following equation into equation 2 we get:

$$
E R p=R^{*}+\beta p E R m-R^{*}
$$

Where beta coefficient

$$
\beta p=\sigma p \sigma m
$$

This equation represents Security Market Line, which we will look at later in this paper. The second part of the equation represents risk premium.

With this result, this equation shows that all investors will choose the same optimal portfolio $M$, just with different weight invested into risk free security, depending on their risk preferences. Looking at the equation we can see that the expected returns are directly connected to the beta coefficient; the higher the beta, the higher will be the risk premium on the security/portfolio. 
As has been already mentioned in this paper, CAPM predicts that all investors will choose the same risky portfolio ' $M$ ', just with different proportions invested in risk-free assets. The choice of wealth invested into risk-free securities will mostly depend on the risk attitudes of the investor. CML is a straight line going from a risk-free rate of return towards the efficiency frontier abc and forms a tangent to portfolio ' $T$ ' (also called the market portfolio). What is essential to mention here is that according to CAPM, all of the efficient portfolios will be located along the CML. Since CML allocates only efficient portfolios, the total risk is represented by standard deviation. $C M L$ is a method of identifying expected rates of return on efficient portfolios; if a portfolio does not lie on the CML, it means that it is either overpriced or underpriced.

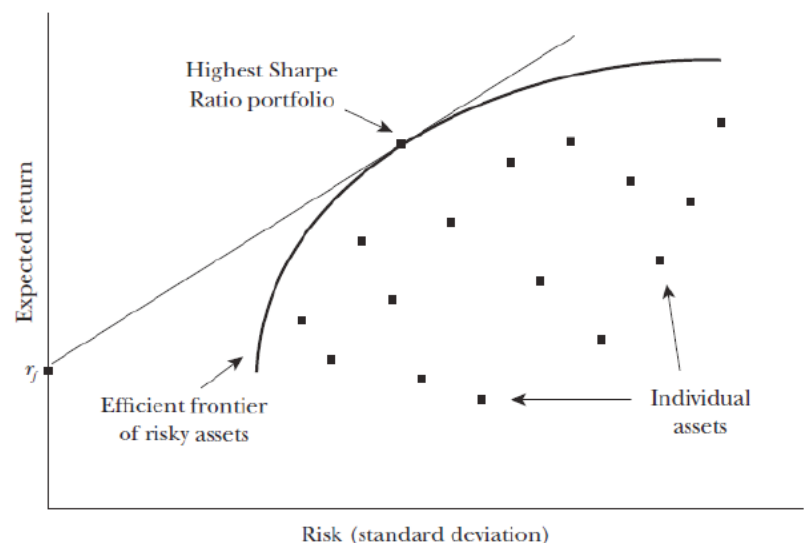

Figure 3: Efficient Frontier with many risky assets.

\section{SECURITY MARKET LINE - SML}

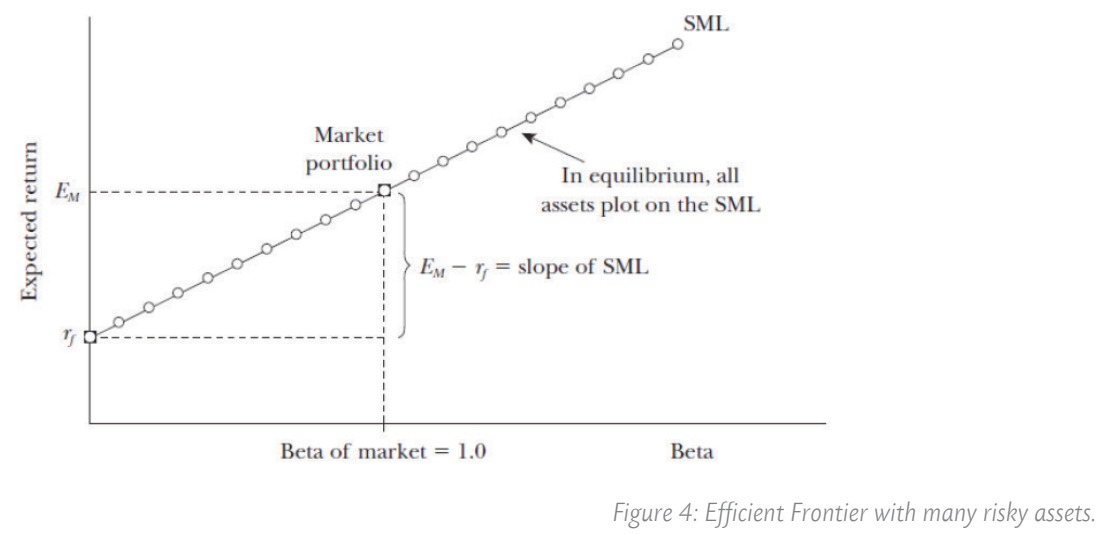

The most important implication of CAPM is a security market line (SML), which one can see above. SML plots the expected returns on the portfolio against its beta coefficient. It is another possible way of rearranging the CAPM equation after CML. The intercept is equal to the risk-free rate of interest and the slope to the excess returns on the portfolio, represented by expected market returns minus risk-free rate of return.

CAPM predicts that all assets (efficient and inefficient) will lie on the SML. Due to this, the total risk is represented by a beta coefficient. This is one of the most widely used practical applications of CAPM. The model predicts that if one plots the average rate of return on a portfolio/asset against its beta, the results will give the SML. 
To summarise everything mentioned about CAPM assumptions and concepts behind it, let us look at the key predictions. There are five key predictions CAPM makes:

1. The intercept ' a' (also called alpha) of the asset should be equal to zero. If alpha is bigger than zero, the CAPM model is missing some variable or other factors to fully explain portfolio excess returns.

2. The beta of an asset, or portfolio, is supposed to be the only explanation of the rate of return on the risky portfolio. The slope of beta should be positive. It also should not have big difference with the risk premium and the average market risk premium.

3. There should be a linear relationship between the beta of the stock, or average portfolio risk, and the average market risk premium.

4. After some time, the market returns or Rm should exceed risk-free rate of return, since market portfolio is riskier than risk-free asset.

5. Explanatory variables like dividend yields, form size, etc., should not prove to be statistically significant to forecast the required rate of return.

\section{EMPIRICAL TESTING}

Due to the complicated nature of CAPM, there have been a lot of arguments 'for' and 'against' the model. In the past 40 years, CAPM has been tested by using different tools and approaches. Generally all empirical tests can be divided into two categories: earlier tests, which were focused more on risk premium testing, tests on beta coefficients, and their relationship with returns, and recent tests, which started in the late 1970 s and were mainly looking at irrational pricing and proxy problems. There were a lot of scientists such as Fama and French (1992), Jensen and Scholes (1972), Blume and Friend (1973), and many more who researched CAPM implementation and presented concerns towards some of the predictions and assumptions of the model.

The reason for all of these debates to my point of view is the complexity of variables composing CAPM. A good example of such is the estimate of the beta coefficient. It is also worth saying that a lot of times the results of the testing have measurement errors and statistical weaknesses, or proxies are chosen wrongly.

There has been some research which is particularly important for our case study. In 1970 Friend and Blume conducted their research on CAPM trying to improve beta estimates for individual securities, then later in 1972, Black, Jensen, and Scholes focused on portfolios. The studies found that beta estimates are more precise on diversified portfolios then on individual securities. That is why later on in this paper, when looking at the Greek Stock Exchange, we will use portfolios instead of individual securities.

Even though generally CAPM proved to hold, the studies done identified weaknesses of CAPM, and it is worth mentioning them. There are 3 key contradictions against the CAPM model:

The estimated intercept ' $a$ ' or alpha is different than zero. This contradicts Prediction 1. The first research which has found that was conducted by Lintner (1965) and Douglas (1968). In 1972, Blank, Jensen, and Scholes tested CAPM by applying regression analysis; they have subsequently proved that intercept is greater than zero, but also that it changes over time. 
The estimated slope ' $b$ ' when positive, tends to be less than the difference between average market returns and the risk-free rate of return. In contradiction to Prediction 2. The Beta coefficient is not the only explanatory variable being important when looking at portfolio returns. Contradiction to Prediction 5. Lintner (1965) and Douglas (1968) found in their research that residual risk has an impact on the expected reruns.

Most of the research acknowledges:

- That there is a linear relationship between the risk on the portfolio or the beta coefficient and its expected returns.

- There is also compliance with the condition that in the long run the expected market portfolio returns tend to exceed the risk-free rate of interest. Prediction 3 and 4.

In this paper we will discover some of these findings in a case study of the Greek Stock Exchange.

This part of the paper is based on the article published in 2006 by the University of Macedonia in Economics.

\section{GREEK STOCK EXCHANGE}

The study focused specifically on the Athens Stock Exchange Market during the period of January 1998 to December 2002. This time period has been chosen due to high returns volatility, which helps to test CAPM prediction better. The sample consists out of 100 companies, which constitute the following indices:

- FTSE/ASE 20 - it is a large cap index containing the 20 largest companies which are also called blue chip companies.

- FTSE/ASE Mid 40 - mid cap index stand for performance of another 40 companies.

- FTSE/ASE Small Cap- this index captures the performance of the next 80 companies.

Each of the series consists of 260 observations of weekly closing prices. Those are the sum of prices at which the stock exchange market is closing the day trading. All of the stocks were chosen according to their trading value to avoid stocks, which are not traded regularly. All of the data has been taken from the MetaStock Data Base, which proves their reliability. The reason why the data has been collected weekly and not monthly or daily was to prevent 'noisy data'. Monthly estimates could result in beta coefficient changes during the set period, whereas daily data could be too noisy to cover.

All stocks were adjusted to dividends, to make a data set fitting the assumptions of CAPM. The ASE Composite Share Index has been used as a proxy for market portfolio and the 3-month Treasury Bill has been chosen for risk-free asset representation. What is crucial to highlight here is that it is better to choose the 3-month treasury bill instead of other maturity periods since it is taken as a benchmark, which reflects market changes better. 
Due to the complexity of the model, the methodology will be divided into 5 steps, each of those will focus on testing of specific predictions of CAPM. Some of the steps are interconnected so it is important to highlight the relationship between the variables in use.

The first step in the investigation of the practicality of CAPM is to estimate the beta of the stocks used in the study. To do this we need to regress each of the stock's weekly returns against the market index, which in our case is represented by the ASE Composite Share Index. The equation below shows the mathematical representation of the above mentioned:

\section{Equation 1}

$$
R_{i t}-R_{f t}=a_{i}+\beta_{i} \cdot\left(R_{m t}-R_{f t}\right)+e_{i t}
$$

Where:

$R_{i t}$ - Is the return on the stock in our case from 1 to 100

$R_{f t}$ - Is the rate of return on risk-free security

$R_{m}$ - The return on the market index

$\beta_{i}$ - The estimate of beta for stock i

$e_{i t}$ - Random disturbance error on the regression.

By applying this equation we get the results shown in the Table 1.

Table 1: Stock beta coefficient estimates (Equation 1)

\begin{tabular}{|c|c|c|c|c|c|c|c|}
\hline STOCK NAME & BETA & STOCK NAME & BETA & STOCK NAME & BETA & STOCK NAME & BETA \\
\hline OLYMP & .0984 & THEMEL & .8302 & PROOD & .9594 & EMP & 1.1201 \\
\hline EYKL & .4192 & AIOLK & .8303 & ALEK & .9606 & NAOYK & 1.1216 \\
\hline MPELA & .4238 & AEGEK & .8305 & EPATT & .9698 & ELBE & 1.1256 \\
\hline MPTSK & .5526 & AEEXA & .8339 & SIDEN & .9806 & ROKKA & 1.1310 \\
\hline FOIN & .5643 & SPYR & .8344 & GEK & .9845 & SELMK & 1.1312 \\
\hline GKOYT & .5862 & SARANT & .8400 & ELYF & .9890 & DESIN & 1.1318 \\
\hline PAPAK & .6318 & ELTEX & .8422 & MOYZK & .9895 & ELBAL & 1.1348 \\
\hline$A B K$ & .6323 & ELEXA & .8427 & TITK & .9917 & ESK & 1.1359 \\
\hline MYTIL & .6526 & MPENK & .8668 & NIKAS & .9920 & TERNA & 1.1392 \\
\hline FELXO & .6578 & HRAKL & .8698 & ETHENEX & 1.0059 & KERK & 1.1396 \\
\hline ABAX & .6874 & PEIR & .8747 & IATR & 1.0086 & POYL & 1.1432 \\
\hline TSIP & .6950 & BIOXK & .8830 & METK & 1.0149 & EEGA & 1.1628 \\
\hline AAAK & .7047 & ELMEK & .8848 & ALPHA & 1.0317 & KALSK & 1.1925 \\
\hline EEEK & .7097 & LAMPSA & .8856 & AKTOR & 1.0467 & GENAK & 1.1996 \\
\hline ERMHS & .7291 & MHXK & .8856 & INTKA & 1.0532 & FANKO & 1.2322 \\
\hline LAMDA & .7297 & DK & .8904 & MAIK & 1.0542 & PLATH & 1.2331 \\
\hline OTE & .7309 & FOLI & .9005 & PETZ & 1.0593 & STRIK & 1.2500 \\
\hline MARF & .7423 & THELET & .9088 & ETEM & 1.0616 & EBZ & 1.2520 \\
\hline MRFKO & .7423 & ATT & .9278 & FINTO & 1.0625 & ALLK & 1.2617 \\
\hline KORA & .7520 & ARBA & .9302 & ESXA & 1.0654 & GEBKA & 1.2830 \\
\hline RYLK & .7682 & KATS & .9333 & BIOSK & 1.0690 & AXON & 1.3030 \\
\hline LYK & .7684 & ALBIO & .9387 & XATZK & 1.0790 & RINTE & 1.3036 \\
\hline ELASK & .7808 & XAKOR & .9502 & KREKA & 1.0911 & KLONK & 1.3263 \\
\hline NOTOS & .8126 & SAR & .9533 & ETE & 1.1127 & ETMAK & 1.3274 \\
\hline KARD & .8290 & NAYP & .9577 & SANYO & 1.1185 & ALTEK & 1.4369 \\
\hline
\end{tabular}

The results here are given in ascending order with the highest beta coefficient of 1.43 is for the ALTEK stock and the lowest of 0.098 for the stock OLYMP. 
The next step will be calculating the average excess returns by using equation 2 below:

\section{Equation 2}

$$
r_{p t}=\frac{\sum_{i=1}^{k} r_{i t}}{k}
$$

Where:

$k$ - The number of the stocks included in each portfolio, in our case from 1-10

$r_{i t}$ - The excess returns on stocks that form each of the portfolios based of $\mathrm{K}$ stock

$r_{p t}$ - The excess returns on the portfolio $\mathrm{p}$, which in our case is from 1-10.

By substituting the results from equation 1 into equation 2, we get the results for average excess returns, which then will be used to form 10 equally weighted portfolios. By forming 10 equal portfolios we are able to spread the beta as much as possible, like this the connection between the beta and the results is clearer. It is also important to acknowledge that by diversifying, we are able to remove most of the specific risk that also helps us to see with the highest precision the effect of beta on the expected returns. To build 10 equally weighted portfolios, we are going to use equation 3 below:

\section{Equation 3}

$$
r_{p t}=a_{p}-\beta_{p} \cdot r_{m t}+e_{p t}
$$

Where:

$r_{p t}$ - Is average excess returns on the portfolio

$\beta_{p}$ - Is the beta coefficient of the portfolio.

By substituting the results from the equation 2 into the equation 3 we are able to get the results shown in Table 2. Table 2 shows the beta coefficients for 10 portfolios, their returns, variance error, and standard deviation of the regression. From the table one can see that the results contradict the prediction of CAPM which says that the higher the beta, the higher the returns.

Table 2: Average excess portfolio returns and betas (Equation 3)

\begin{tabular}{|l|l|l|l|l|}
\hline PORTFOLIO & $\mathbf{r}_{\text {p }}$ & BETA (P) & VAR. ERROR & $\mathbf{R}^{\mathbf{2}}$ \\
\hline a10 & .0001 & .5474 & .0012 & .4774 \\
b10 & .0000 & .7509 & .0013 & .5335 \\
c10 & -.0007 & .9137 & .0014 & .5940 \\
d10 & -.0004 & .9506 & .0014 & .6054 \\
e10 & -.0008 & .9300 & .0009 & .7140 \\
f10 & -.0009 & .9142 & .0010 & .6997 \\
g10 & -.0006 & 1.0602 & .0012 & .6970 \\
h10 & -.0013 & 1.1066 & .0019 & .6057 \\
i10 & -.0004 & 1.1293 & .0034 \\
j10 & -.0004 & 1.2024 & .0026 & .5691 \\
Average $R_{f}$ & .0014 & & & \\
Average $r_{m}=\left(R_{m}-R_{f}\right)$ & .0001 & & \\
\hline
\end{tabular}

International Research Journal of Finance and Economics, Issue 4 (2006), 85. Source: Metastock (Greek) Data Base and calculations (S-PLUS).

Table 2 clearly shows that the return on the portfolio j10 with the highest beta coefficient is lower than of the portfolio a10 with the lowest beta coefficient. It is also true that the returns on the higher beta coefficients are negative. What is also worth mentioning here is the average risk-free rate of return, which is 0.0014 and the return on the risk market portfolio, which is 0.0001 . In this case, we can see that the returns on the riskfree security would be the same as on the portfolio a10, which has the highest returns. 


\section{Equation 4}

$$
r_{P}=\gamma_{0}+\gamma_{1} \cdot \beta_{P}+e_{P}
$$

The next step is to estimate the SML by taking the average excess returns on the portfolios and regressing them against the betas of the portfolios. This step is done on the ex-post bases, which means that we are building our forecasts on historical data. The equation showing this relationship is given below:

The beta coefficient of the portfolio is taken from equation 3. To test if the predictions of CAPM in regards to SML hold, we need to add additional variables:

$\gamma_{1}$ - The market price of risk or in other words the risk premium

$\gamma_{0}$ - The expected return on the zero-beta asset/portfolio, or the intercept

$e_{p}$ - The random disturbance error in the regression analysis.

The results of equation 4 can be seen in Table 3. To test if CAPM holds, we need to see if the intercept of the SML is zero. In our case, the intercept is represented by $\gamma_{0}$. Looking at the table we can see that the $\gamma_{0}$ is not exactly zero, but is not much more significant in a statistical point of view. It is also true that the correlation coefficient between $\gamma_{0}$ (the intercept) and $\gamma_{1}$ (the slope) is high 0.98, which shows that CAPM explains the excess returns.

Table 3: Statistics of the estimation of the SML (Equation 4)

\begin{tabular}{|l|l|l|}
\hline COEFFICIENT & $\gamma_{0}$ & $\gamma_{1}$ \\
\hline Value & .0005 & -.0011 \\
t-value & $(.9011)$ & $(-1.8375)$ \\
p-value & .3939 & .1034 \\
\hline Residual standard error: .0004 on 8 degrees of freedom & \\
Multiple R-Squared: .2968 & \\
F-statistic: 3.3760 on 1 and 8 degrees of freedom, the p-value is .1034 \\
Correlation of Coefficients $\mathrm{p}_{\gamma 0 \cdot \gamma 1}-.9818$
\end{tabular}

From the results of equation 4, we can see that by examining SML we cannot reject CAPM. Another prediction of the CAPM is that the slope of SML will be equal to the excess returns on the market portfolio; however one can see that if we take the excess returns on the market portfolio 0.0001 from Table 2 and compare them to the results of the slope $\gamma_{I}-0.0011$ in Table 3, they are quite different.

The next step will be testing the prediction 3 of the CAPM hypothesis. The third prediction talks about the linear relationship between the portfolio returns and the beta coefficient. To do that we regress them and also add an extra variable which is beta coefficient squared. The described steps can be seen in equation 5 below:

\section{Equation 5}

$$
r_{p}=\gamma_{0}+\gamma_{1} \cdot \beta_{p}+\gamma_{2} \cdot \beta_{p}^{2}+e_{p}
$$

Where:

$\beta_{p}$ - beta and beta squared has been taken from equation 3

$\gamma_{2}$-Stands for nonlinearities in SML and should be equal to zero, the rest of the variables stay the same as in the equation 4 above. 
The results from this equation can be seen in Table 4 below.

Table 4: Testing for non-linearity (Equation 5)

\begin{tabular}{|l|l|l|l|}
\hline COEFFICIENT & $\gamma_{0}$ & $\gamma_{1}$ & $\gamma_{2}$ \\
\hline Value & .0036 & -.0084 & .0041 \\
t-value & $(1.7771)$ & $(-1.8013)$ & $(1.5686)$ \\
p-value & .1188 & .1147 & 0.1607 \\
\hline Residual standard error: .0003 on 7 degrees of freedom & \\
Multiple R-Squared: .4797 & \\
F-statistic: 3.2270 on 2 and 7 degrees of freedom, the p-value is .1016 & \\
\hline
\end{tabular}

International Research Journal of Finance and Economics, Issue 4 (2006), 85

From this table we can make the following conclusions: the intercept is still bigger than 0 , even though still statistically not significant. It is also true that it has been greater than the risk-free interest rate of 0.0014 . These results show a contradiction with the CAPM assumption that SML goes from the risk-free interest rate. The slope of the SML is negative and different from zero. The coefficient $\gamma_{2}$ is very small and statistically different from zero, which means that a CAPM assumption regarding linear relationship holds. The standard error is small, which means that the results are statistically reliable.

A further step is to examine prediction 5 of the model, which states that no other variables different than beta explain the expected returns on portfolios. To test this hypothesis we add another variable ' residual risk', or in simple words, an unknown risk. In finance this risk is most of the times referred to as unsystematic or company/asset specific risk. To do this, equation 5 has been improved by adding two additional variables.

\section{Equation 6}

$$
r_{p}=\gamma_{0}+\gamma_{1} \cdot \beta_{p}+\gamma_{2} \cdot \beta_{p}^{2}+\gamma_{3} \cdot R V_{p}+e_{p}
$$

Where:

$R V_{p}$ - Is the residual variance of the portfolio returns

$\gamma_{3}$ - Stands for residual risk, according to the CAPM assumptions this should be equal to zero. The rest of the variables stayed the same as in the equation 5.

The results from equation 6 can be seen in Table 5 below. Since CAPM states that no other variables than beta can explain the excess returns on the portfolio, the coefficient $\gamma_{3}$ should be equal to zero. In Table 5 we can see that it is very small and statistically not significant from zero. From this one can conclude that the CAPM assumption holds. The residual standards error is also very small. The T-value which measures how many standard errors the coefficient is away from zero is less than 2.

Table 5: Testing for non-systematic risk (Equation 6)

\begin{tabular}{|l|l|l|l|l|}
\hline COEFFICIENT & $\gamma_{0}$ & $\gamma_{1}$ & $\gamma_{2}$ & $\gamma_{3}$ \\
\hline Value & .0017 & -.0043 & .0015 & .3505 \\
t-value & $(.5360)$ & $(-.6182)$ & $(.3381)$ & $(.8035)$ \\
p-value & .6113 & .5591 & .7468 & .4523 \\
\hline Residual standard error: .0003 on 6 degrees of freedom & & \\
Multiple R-Squared: .5302 & & \\
F-statistic: 2.2570 on 3 and 6 degrees of freedom, the p-value is .1821
\end{tabular}


CAPM has been a great development in the world of finance. It is widely used by different market participants, to determine not only the future returns on securities, but the risk associated with that security/ asset. The idea behind the model was built on that of Portfolio Theory developed by Markowitz and afterwards improved by James Tobin. Portfolio theory has been a crucial development and the concepts it brought into the pricing of securities and management of the returns are essential for the optimisation of resources. Diversification allowed investors to spread the risk and to find the best optimal portfolio for their risk preferences.

CAPM goes beyond this notion and develops it even more. Now we are not only looking at the portfolio/ asset expected returns individually, but we are linking them to the overall market condition and fluctuations. By correlating them, we predict how the portfolio will react to certain market conditions. To do this CAPM introduces a beta coefficient. Beta of the stock not only shows it riskiness, but also predicts its returns since risk-premium is a giver per unit, of beta or risk. From this, one of the most important CAPM predictions is built; the higher the beta coefficient the higher are the expected returns.

In the case study of the Greek Stock Exchange we could see that this prediction did not work on this specific market. The results of the research done by the University of Macedonia and published in the International Research Journal of Economics in 2006 have shown the following:

- The result of the study of ASE contradicts the CAPM assumption that the higher the beta coefficient the higher the returns (Table 1).

- The results received from the Table 2 and 3 show that the model explains the excess returns.

- CAPM predicts that the value of the intercept should be zero and the slope of SML should be equal to the excess returns of the market portfolio (risk premium) the findings of this case study contradict this hypothesis (Table 3).

- The test for non-linearity has shown that there is a linear relationship between the average excess returns on the portfolio and its beta coefficient (Table 4).

- Finally, according to the results from Equation 6, beta is the only explanatory variable for portfolio excess returns and residual risk has no effect on the expected return.

The case study of the Athens Stock Exchange has shown some evidence against CAPM; however, it does not mean that the data completely rejects the model. The following result has measurement errors that might have occurred due to the proxies the case study took as its foundations. This is very crucial to understand since most of the empirical tests are very dependent on the proxies they take as given variables of the model. The results of such empirical tests can have much debate on relevance. Due to all of these factors, most of the finance professionals still use CAPM as one of the tools, by combining it with other methods. The model is still taken as one of the most accurate and reliable tools. 


\section{REFERENCES}

Black, F., Jensen, M. C. and Scholes, M. (1972) The Capital asset pricing model: Some empirical tests. Studies in the Theory of Capital Markets. p. 79-121. New York: Praeger.

Black, F. (1993) Beta and return. Journal of Portfolio Management No. 20, p. 8-18.

Blume, M. (1975), ' Betas and their regression tendencies', Journal of Finance No. 30, p. 785-795.

Coolidge, F.L. (2006) Statistics: A Gentle Introduction. Ch. 6, p. 153-161.

Fama, E. and K. French (1993), ' Common risk factors in the returns on stocks and bonds', Journal of Financial Economics No. 33, p. 3-56.

Fama, E.F. and French, K.R. (2004) 'The CAPM: Theory and Evidence', Journal of Economic Perspectives, Vol 18, No. 3, 2004.

FTSE/ASE Indices (Available at: http://www.capitallink.com/indices/indices.php3?page=View\%20ASE\%2040)

International Research Journal of Finance and Economics, Issue 4 (2006) 'Testing the CAPM: The Case of the Emerging Greek Securities Market', University of Macedonia.

Levy, H. (2011) The Capital Asset Pricing Model in the 21st Century. Analytical, Empirical and Behavioral Perspectives. Cambridge. Mabrouk, H.B. and Bouri, A. (2010) 'The Quarrel on the CAPM: A Literature Survey', June 2010, Vol. 2, No. 2.

Markowitz, H. (Mar., 1952), ' Portfolio Selection', The Journal of Finance, Vol. 7, No. 1, p. 77-91.

Pilbeam, K. (2010) Finance and Financial Markets. Ch. 8, 3rd Ed.

R.E. Bailey (2005) The Economics of Financial Markets. Ch. 6, p. 143.

\section{Tables and Figures}

Figure 1: André F. Perold (2004) Journal of Economic Perspectives-Vol 18, No. 3, p. 12.

Figure 2: Eugene F. Fama and Kenneth R. French "The CAPM: Theory and Evidence", Journal of Economic Perspectives, Vol 18, No. 3, 2004.

Figure 3: André F. Perold (2004) Journal of Economic Perspectives-Vol 18, No. 3, p. 12.

Figure 4: André F. Perold (2004) Journal of Economic Perspectives-Vol 18, No. 3, p. 18.

Table 1: International Research Journal of Finance and Economics, Issue 4 (2006), p. 84.

Table 2: International Research Journal of Finance and Economics, Issue 4 (2006), p. 85.

Table 3, 4: International Research Journal of Finance and Economics, Issue 4 (2006), p. 86

Table 5: International Research Journal of Finance and Economics, Issue 4 (2006), p. 87.

\section{Equations}

Equation 1: International Research Journal of Finance and Economics, Issue 4 (2006), p. 82.

Equation 2 - 6: International Research Journal of Finance and Economics, Issue 4 (2006), p. 83 